\title{
Electrophysiological correlates of aesthetic processing of webpages: A comparison of experts and laypersons
}

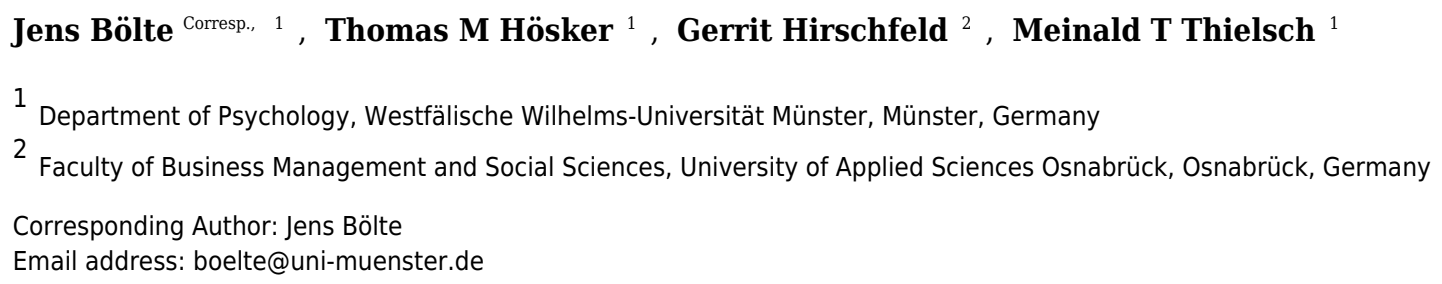

We investigated whether design experts or laypersons evaluate webpages differently. Twenty participants, 10 experts and 10 laypersons, judged the aesthetic value of a webpage in an EEG-experiment. Screenshots of 150 webpages, judged as aesthetic or as unaesthetic by another 136 participants, served as stimulus material. Behaviorally, experts and laypersons evaluated unaesthetic webpages similarly, but they differed in their evaluation of aesthetic ones: Experts evaluated aesthetic webpages as unaesthetic more often than laypersons did. The ERP-data show main effects of level of expertise and of aesthetic value only. There was no interaction of expertise and aesthetics. In a timewindow of 110-130 ms after stimulus onset, aesthetic webpages elicited a more negative EEG-amplitude than unaesthetic webpages. In the same time window, experts had more negative EEG-amplitudes than laypersons. This patterning of results continued until a time window of 600-800 ms in which group and aesthetic differences diminished. An interaction of perceiver characteristics and object properties that several interactionist theories postulate was absent in the EEG-data. Experts seem to process the stimuli in a more thorough manner than laypersons. The early activation differences between aesthetic and unaesthetic webpages is in contrast with some theories of aesthetic processing and has not been reported before. 
1 Electrophysiological correlates of aesthetic processing of webpages: A comparison of experts

2 and laypersons

5 2Faculty of Business Management and Social Science, University of Applied Science Osnabrück,

11 Corresponding author:

12 Jens Bölte

13 Department of Psychology

14 Westfälische Wilhelms-Universität Münster

15 Fliedner Str. 21

1648159 Münster, Germany 


\section{Abstract}

We investigated whether design experts or laypersons evaluate webpages differently.

20 Twenty participants, 10 experts and 10 laypersons, judged the aesthetic value of a webpage in an

21 EEG-experiment. Screenshots of 150 webpages, judged as aesthetic or as unaesthetic by another

22136 participants, served as stimulus material. Behaviorally, experts and laypersons evaluated

23 unaesthetic webpages similarly, but they differed in their evaluation of aesthetic ones: Experts

24 evaluated aesthetic webpages as unaesthetic more often than laypersons did. The ERP-data show

25 main effects of level of expertise and of aesthetic value only. There was no interaction of

26 expertise and aesthetics. In a time-window of 110-130 ms after stimulus onset, aesthetic

27 webpages elicited a more negative EEG-amplitude than unaesthetic webpages. In the same time

28 window, experts had more negative EEG-amplitudes than laypersons. This patterning of results

29 continued until a time window of $600-800 \mathrm{~ms}$ in which group and aesthetic differences

30 diminished. An interaction of perceiver characteristics and object properties that several

31 interactionist theories postulate was absent in the EEG-data. Experts seem to process the stimuli

32 in a more thorough manner than laypersons. The early activation differences between aesthetic

33 and unaesthetic webpages is in contrast with some theories of aesthetic processing and has not

34 been reported before. 


\section{Introduction}

Humans appreciate aesthetic entities in various contexts: Entities might be created for aesthetic and intellectual purposes only as in fine arts. Aesthetic properties of a product might serve to attract customers. Humans evaluate the aesthetic properties of everyday objects such as tableware, TV-sets, or food. Aesthetic judgments play a role in many aspects of human life

41 (Hoyer \& Stokburger-Sauer, 2012) differing between cultures, situations, educational background, expertise and other individual properties (Jacobsen, 2006).

We focus in our research on the differences that experts and laypersons might show in evaluating the aesthetic quality of webpages. Experts and laypersons differ in their aesthetic judgments in various domains such as art, music, movies, software code, or even facades of houses (Hasse \& Weber, 2012; Kozbelt, Dexter, Dolese \& Seidel, 2012; Müller, Höfel, Brattico \& Jacobsen, 2009; Silvia, 2013; Silvia \& Berg, 2011). Websites are a modern medium of communication serving nearly every aspect of human living. They are evaluated not only in terms of functionality but also in terms of their aesthetic properties (Lavie \& Tractinsky, 2004; Moshagen \& Thielsch, 2010). While electrophysiological responses to music, for instance, have

51 been described (Müller et al., 2009; Müller, Höfel, Brattico \& Jacobsen, 2010), it is unclear whether similar event-related potentials will be present when evaluating webpages.

\section{Aesthetics of websites}

Aesthetics has become a core construct in research on human computer interaction.

Similar to other everyday stimuli such as logos (Handy et al., 2010), webpages (Lindgaard et al., 2006; Thielsch \& Hirschfeld, 2012; Tractinsky, Cokhavi, Kirschenbaum \& Sharfi, 2006) are 
58 Yet, website aesthetics, i.e. the "immediate pleasurable subjective experience that is directed

59 toward an object and not mediated by intervening reasoning" (Moshagen \& Thielsch, 2010, p.

60 690), is not only influencing early perceptive stages but also later processing, such as the

61 formation of behavioral intentions (Moshagen \& Thielsch, 2010; Thielsch, Blotenberg \& Jaron,

62 2014). Aesthetics has an impact on various constructs: for example, perceived usability,

63 credibility, satisfaction, preference, urge to buy impulsively, or intention to revisit (for overviews

64 see Lee \& Koubek, 2012; Moshagen \& Thielsch 2010; Tuch, Roth, Hornbæk, Opwis \& Bargas-

65 Avila, 2012b).

66 The current research suggests that aesthetic responses to webpages occur immediately at

67 first sight (e.g., Lindgaard et al., 2006 \& 2011; Thielsch \& Hirschfeld, 2012; Tractinsky et

68 al., 2006). This is not only in line with results of prior research on the aesthetics of art, but as

69 well of high practical relevance, as users' first impressions are very relevant for the decision to

70 explore a particular website more thoroughly or leave it for another (see Thielsch et al., 2014).

71 However in contrast to pieces of art, the major purpose of a website is not to elicit an aesthetic

72 experience. Websites are mostly designed to provide some kind of information, typically in an

73 interactive manner (see ISO, 2006; Thielsch et al., 2014).

\section{Models of aesthetic processing}

Fechner (1876) pioneered the empirical investigation of aesthetic processing and started the empirical search for object properties that determine the subjective aesthetic evaluation. Following this approach, a number of properties have been discussed, e.g. balance and proportion (Arnheim, 1974; Birkhoff, 1933; Fechner, 1876), novelty and prototypicality (Hekkert, Snelders \& van Wieringen, 2003; Hekkert \& van Wieringen, 1990), contrast and clarity (Gombrich, 1995; Solso, 2003) as well as the relation between object features, particularly 
81 between simplicity and complexity (Birkhoff, 1933; von Ehrenfels, 1890; Eysenck, 1941). In

82 recent years, interactionist perspectives on aesthetics have been put forward focusing on the

83 interplay between the observer and the object (e.g., Berlyne, 1971; Chatterjee, 2004; Jacobsen, 84 2006; 2010; Leder, Belke, Oeberst \& Augustin, 2004; Leder \& Nadal, 2014; Reber, Schwarz \&

85 Winkielman, 2004). This perspective promotes the idea that aesthetic processing operates on 86 distinct processing stages.

According to the framework by Leder et al. (2004; Leder \& Nadal, 2014), aesthetic processing follows five stages: perception, implicit classification, explicit classification, cognitive mastering and evaluation. Affective states accompany cognitive processing in an interactive manner. The cognitive processing results in two outcomes: First, the aesthetic

91 judgment reflecting the degree by which the object in question meets the normative standards of 92 aesthetics. Second, the aesthetic emotion or appraisal is characterized by the affective 93 experiences during the aesthetic processing. Whereas this framework of aesthetic appreciation and aesthetic judgments (Leder et al., 2004) emphasizes psychological processes, the model of visual neuroaesthetics by Chatterjee (2004) focuses on the neuronal basics of aesthetic processing. Early and intermediate visual

97 processing steps are similar for aesthetic and non-aesthetic processing in this model. During 98 early vision, basic stimulus parameters such as color, shape and contrast are processed (Marr, 99 1982). Thereafter during intermediate vision, the stimulus parameters are grouped together. At 100 the latest processing stage, object recognition, affective and aesthetic evaluation take place.

101 Aesthetically relevant object features trigger attention processes during early and intermediate 102 stages of visual processing. Thereby, the processing of the aesthetic characteristics is enhanced 103 in later phases of visual processing in terms of a feed forward system (Chatterjee, 2004). 


\section{EEG-studies on aesthetic processing}

105 EEG-studies are a valuable tool to shed some light on the timing of aesthetic processing.

106 The comparison of aesthetic and descriptive assessments of geometric patterns showed that

107 aesthetic processing is a two-step process characterized by an early frontal negative potential

108 (ERAN) between 300 and $400 \mathrm{~ms}$ after stimulus onset that is more negative for unaesthetic

109 stimuli compared to aesthetic ones. This difference between stimuli is diminished when

110 participants have to judge whether the stimulus is symmetric or not. The second step is

111 associated with a late positive potential (LPP) in central and parietal electrodes between 440 and

$112880 \mathrm{~ms}$ peaking around $600 \mathrm{~ms}$ after stimulus onset. Again the LPP is more positive going for

113 aesthetic images than for unaesthetic images and only found when participants have to rate the

114 aesthetics of an image. The ERAN supposedly reflects impression formation, while the LPP

115 indicates evaluative stimulus categorization (Höfel \& Jacobsen, 2007a; Höfel \& Jacobsen,

116 2007b; Jacobsen \& Höfel, 2003).

117 De Tommaso et al. (2008) first asked their participants to categorize targets (images of

118 paintings or geometric figures) as beautiful, neutral or ugly and to ignore standard stimuli (a

119 green screen). In a second session, they asked participants to categorize targets as known or

120 unknown. ERPs in these two sessions were scrutinized for differences between beautiful, neutral

121 and ugly pictures. In the first session, the authors found a main-effect for the rated aesthetics of

122 the pictures on the N2b amplitude - with neutral, beautiful and ugly pictures showing a larger

$123 \mathrm{~N} 2 \mathrm{~b}$ compared to the standard stimuli. No interactions with task or electrode were found. For the

$124 \mathrm{P} 3 \mathrm{~b}$, all main effects were significant indicating more positive responses to beautiful pictures, the

125 artistic task and at parietal electrodes. In Experiment 2, N2b-amplitudes showed no modulation

126 due to aesthetic value. However, beautiful target stimuli elicited a larger P3b than ugly or neutral 
127 target stimuli, all of which elicit a larger P3b than standard stimuli. The authors argue that task

128 differences bring about the different results; however, they did not formally test for differences

129 between the tasks. Together these studies showed that both early (N2b) as well as late effects

130 occur (P3b, ERAN, LPP), at least when the task is to evaluate the aesthetic value of the stimuli.

131 Using an oddball-paradigm, Wang, Huang, Ma and Li (2012) investigated the processing

132 of aesthetic and unaesthetic images without explicitly instructing their participants to form

133 aesthetic judgements. They observed a P2 component, the only component that they report, that

134 was most pronounced at frontal sites and enhanced for less beautiful pendants in comparison to

135 more beautiful pendants. A P2 supposedly indicates early affective evaluation, for instance of

136 words or pictures that elicit negative feelings (Huang \& Luo, 2006). Therefore, Wang et al.

137 concluded that the P2 they observed reflects early automatic emotional processes that accompany

138 aesthetic processing. Alternatively, Carretié, Mercado, Tapia and Hinojosa (2001) suggested that

139 attentional processes might be involved in the P2. Given that Wang et al. used an oddball-

140 paradigm that is suited to investigate automatic attentional processes, this alternative

141 interpretation cannot be ruled out. Carretié, Hinojosa, Martín-Loeches, Mercado and Tapia

142 (2004) suggest that the P2 does not only reflect low-level feature processing, but rather shows

143 the effect of attentional and emotional characteristics of the stimuli.

\section{Individual differences: Experts versus laypersons}

145 The above-mentioned empirical findings reveal the impact of stimulus properties on the

146 different suggested processing steps (Chatterjee, 2004; Jacobsen, 2006; Leder et al., 2004).

147 However, varying subject characteristics such as age (Thielsch, 2008), gender (Cela-Conde et al.,

148 2009; Tuch, Bargas-Avila \& Opwis, 2010) or domain specific expertise that could influence

149 aesthetic processing were not taken into account (Chevalier \& Ivory, 2003; Park, Choi \& Kim, 
150 2004). Especially, the model by Leder et al. that refers to implicit or explicit knowledge in long-

151 term memory allows predicting differences in processing by experts and laypersons.

152 In the context of face perception research, it has been shown that expertise for face-like

153 objects can be acquired by training (e.g., Gauthier \& Tarr, 1997) and that the processing of faces

154 or other well-trained materials goes along with distinct brain activity (Bentin, Allison, Puce,

155 Perez \& McCarthy, 1996; Gauthier, Skudlarski, Gore \& Anderson, 2000; Tanaka \& Curran,

156 2001). Thus, expertise for specific objects can be acquired and is reflected in distinguishable

157 cortical activity (Scott, Tanaka, Sheinberg \& Curran, 2006).

158 For example, architects show higher hippocampus, precuneus, orbitofrontal cortex and

159 gyrus cinguli activity than laypersons when asked to rate the aesthetics of buildings (Kirk, Skov,

160 Christensen \& Nygaard, 2009). Moreover, designer and laypersons differ in their cortical activity

161 during a design task (Kowatari et al., 2009). Similarly, art specific expertise is accompanied by

162 functional and structural modifications, i.e. higher cortical activation during color processing and

163 higher density of grey matter in area V4 (Long, Peng, Chen, Jin \& Yao, 2011). Furthermore,

164 laypersons and experts differ in perceptual exploration (Hekkert \& van Wieringen, 1996),

165 processing of complexity (Reber et al., 2004) and aesthetic preferences (Hekkert \& van

166 Wieringen, 1996). Expertise is presumably characterized by stronger than usual neuronal

167 connections of specific representations or processes which result in high accessibility of these

168 representations (Cheung \& Bar, 2012; Harel, Gilaie-Dotan, Malach \& Bentin, 2010).

Müller et al. (2010) investigated the differential processing of short piano sequences by

170 laypersons and experts using EEG. They observed a larger frontal P2 amplitude for experts than

171 for laypersons - possibly the same component as studied by Wang and colleagues (2012) - and a

172 larger ERAN, which peaked $200 \mathrm{~ms}$ after stimulus onset. Müller et al. assumed that the enhanced 
173 P2 reflects extended neural representations for musical stimuli in experts. The larger ERAN

174 indicates a more thorough processing of the stimuli by the experts than by the laypersons

175 because it was only observed with mild harmonic violations.

176 Using paintings, filtered copies of these paintings and plain-color stimuli as visual

177 stimuli, Pang, Nadal, Müller-Paul, Rosenberg and Klein (2013) could show that paintings elicit

178 larger P3b components than their filtered copies or plain-color stimuli in a free-viewing task.

179 Experts, determined by a questionnaire, had smaller P3b/LPC-like bilateral posterior ERPs than

180 laypersons. Pang et al. argued that this reduced activity is a consequence of neural efficiency due

181 to increased practice that is also reflected in non-directive tasks. Clearly, this observation

182 contradicts the one reported by Müller et al. (2010). Müller et al. observed increased neuronal

183 activation for experts in comparison to laypersons. However, various differences between the

184 experiments, visual vs. auditory stimulation, passive viewing vs. explicit judgment, and choice of

185 reference electrodes, prohibit firm conclusions. The idea that expertise is associated with

186 stronger neuronal connections between cortical areas involved in stimulus processing is

187 compatible with both increased as well as decreased activations for experts compared to

188 laypersons (Cheung \& Bar, 2012; Harel et al., 2010). Taken together, the research has revealed

189 several differences between experts and laypersons when it comes to the processing of aesthetic

190 stimuli. It is unknown whether these differences map to the processing stages surmised by

191 current models of aesthetic perception (Chatterjee, 2004; Jacobsen, 2006; Leder et al., 2004).

\section{Research question}

The research presented above shows that experts and laypersons differ in the processing

194 of stimuli, including the evaluation of aesthetic stimulus qualities. Most often music or stimuli

195 constructed for the particular research question were used as stimulus material. We want to 
196 extend this research by using commonly experienced stimuli such as webpages. Since studies

197 depending on design, stimuli and task-type resulted in vastly different ERP-components that

198 were modulated by aesthetics and expertise, we tested for differences in those time-windows that

199 corresponded best to the ERP found in this study.

Materials and Methods

201

202

203

204

205

206

207

208

209

210

211

212

213

214

215

216

217

\section{Participants}

There were 20 participants, 10 were experts (mean age: 32.2 years, $S D=12.5$ years, $M i n$ $=22, \operatorname{Max}=62,5$ females) and 10 laypersons (mean age: 31 years, $S D=11.4$ years, $\operatorname{Min}=20$, Max $=62,5$ females). In addition, laypersons were also matched to experts in terms of education. Experts were either professionals in or students of design, graphic design or digital media design. They had a mean experience in the area of 10.8 years $(S D=10.7$ years). Experts attached more value to the visual-aesthetic product design than laypersons in the Centrality of Visual Product Aesthetics questionnaire (CVPA; Bloch, Brunel \& Arnold, 2003; German version Thielsch, 2008; experts: $M_{\mathrm{CVPA}}=4.18, S D=.41$; laypersons: $M_{\mathrm{CVPA}}=2.9, S D=.52 ; t(18)=6.08, p<$ $.001, d=1.6)$.

Participants received $10.00 €$ for their participation. They had unimpaired or corrected-tonormal visual acuity as well as normal color perception. Our study did not require the approval of our local Ethics Committee at the Department of Psychology at the University of Münster as we performed a non-clinical website evaluation study and used only non-invasive measures (ratings, reaction times, EEG). The participants' task was to assess the aesthetic values of webpages. No treatments or false feedbacks were given; no potential harmful evaluation methods were used. Participation was voluntary and participants could drop out at any time without any 
218 negative consequences. Informed consent was obtained from all participants. All data were

219 stored using an anonymous ID for each participant.

\section{Materials}

We used 150 webpage-screenshots in the experiment. These screenshots were selected

222 from a larger set of 300 webpage-screenshots that had been rated in terms of their aesthetic 223 attractiveness by another 136 participants (mean age: 25.2 years, $S D=6.77$ years, 110 females)

224 using the short version of the Visual Aesthetics of Websites Inventory (VisAWI-S, Moshagen \& 225 Thielsch, 2013). Websites known by more than $25 \%$ of the participants were excluded from

226 further analysis. Based on the results, two sets of 75 webpage-screenshots were created differing 227 significantly in aesthetic assessment $\left(M_{\text {aesthetic }}=5.11, S D=.39 ; M_{\text {unaesthetic }}=3.27, S D=.45 ; d=\right.$ $\left.2285.76 ; \chi^{2}=146.03, p<.001\right)$. The webpage-screenshots come from ten different content domains 229 (download \& software, e-commerce, e-learning, entertainment, e-recruiting, information, 230 corporate websites, social software, search engines and web portals). Information about the 231 browser was removed using Adobe Photoshop, Version CS5.1 C. Webpages were $1280 \times 780$ to 2321264 x 765 pixels large (unaesthetic mean: 1012742 pixel, SD: 5820, aesthetic mean: 1013931 233 pixel, SD: 5278 ; Welch $t(146.61)=-1.31, p=.192)$, resulting in a visual angle of maximally $23418.23^{\circ}$. The average luminance per pixel relative to white (white having a value of 1.0 , black 235 having a value of 0 ) did not differ from each other (unaesthetic mean: .785, SD: 0.149, aesthetic: 236 .739, SD: 0.182; Welch $t(142.63)=1.677, p=.095)$. Also, unaesthetic and aesthetic webpages 237 did not differ in contrast (unaesthetic: .261, SD: 0.069, aesthetic: .252, SD: 0.068; Welch $238 t(147.93, p=.408)$. Aesthetic and unaesthetic webpages differed in complexity measured in byte 239 (see Miniukovich \& De Angeli, 2015; Tuch et al. 2009; unaesthetic mean: 681 kb, SD: 199; 240 aesthetic: mean: $578 \mathrm{~kb}$, SD: 147 ; Welch $t(136.55)=3.59, p<.001)$. The later difference might 
241 reflect design differences between unaesthetic (e.g. cluttered layout) and aesthetic webpages

242 (e.g., clear, structured layout). ${ }^{1}$

\section{Apparatus}

The experiment was controlled by Presentation Version 16.04.25.12 (Neurobehavioral

Systems, Albany, CA, USA). Stimuli were presented on a Samsung Sync-Master 2233, 1680 x

247 RB 830. The EEG was digitized with a sampling frequency of $256 \mathrm{~Hz}$ using 32 sintered

$248 \mathrm{Ag} / \mathrm{AgCL}-\mathrm{electrodes}$ placed according to the 10-20 system (Advanced Neuro Technology,

249 Enschede, The Netherlands) and two mastoid electrodes. We used an online low-pass half-power

250 filter of $69.12 \mathrm{~Hz}$ and an average reference for recording. Impedance was kept below $5 \mathrm{kOhm}$.

251 Vertical EOG was measured by placing a bipolar electrode beneath and above the left eye.

252 Horizontal EOG was measured by placing a bipolar electrode at the outer canthus of each eye.

253 AFz was used as ground electrode.

\section{Procedure}

All participants were interviewed via a telephone-interview in which demographic information, handedness, visual acuity, neurological or psychiatric disorders were assessed. Upon arrival in laboratory, participants were informed about the course of the experiment. First, they completed the Centrality of Visual Product Aesthetics questionnaire (CVPA; Bloch et al., 2003; German version Thielsch, 2008). Afterwards, participants were asked to assess the 260 aesthetics of a given webpage. 
263 presented to $250 \mathrm{~ms}$ in screen center, after this a uniformly light-grey screen was displayed for

$2641250 \mathrm{~ms}$, followed by displaying the webpage-screenshot for $2500 \mathrm{~ms}$. Again, a light grey screen

265 was displayed for $500 \mathrm{~ms}$ when three exclamation marks appeared to signal the participants to

266 give their aesthetic judgment (aesthetic or unaesthetic) by pressing one of two keys. Participants

267 were instructed to move as little as possible during recording. Specifically, they were asked to

268 refrain from moving their eyes during the presentation of the webpage and blink after the offset

269 of the webpage. There were short breaks of $10-15$ seconds duration every $90-120$ seconds and

270 a longer break of $90-135$ seconds every $7.5-9.0$ minutes. The experiment lasted about 25

271 minutes. In total, 150 stimuli (75 aesthetic and 75 unaesthetic) were presented once in random

272 order determined for each participant.

\section{Data analysis}

The EEG-data were re-referenced to linked mastoids. An offline bandpass-filter (half-

275 power: .1 - 25 Hz) was applied. An EEG larger than $+/-75 \mu \mathrm{V}$ was considered an artifact.

276 Artifact free epochs of $1200 \mathrm{~ms}$ length with a baseline of $200 \mathrm{~ms}$ were defined.

277

We used only congruent trials to calculate averages. A trial was considered congruent if

278

279 resulted in 705 artifact-free aesthetic trials (experts: 292 i.e. $39 \%$ of the trials, laypersons: 413 i.e. 55\%) and 1136 artifact-free unaesthetic trials (experts: 541 i.e. $72 \%$, laypersons: 595 i.e. 79\%) that were averaged. Based on visual inspection of the ERP, we calculated mean voltage per 282 participant and condition in the following time-windows $80 \mathrm{~ms}-105 \mathrm{~ms}, 110 \mathrm{~ms}-130 \mathrm{~ms}$, $283150 \mathrm{~ms}-370 \mathrm{~ms}, 370 \mathrm{~ms}-600 \mathrm{~ms}$ and $600 \mathrm{~ms}-800 \mathrm{~ms}$ after stimulus onset. Electrodes were 284 grouped into lateral-central position (left: F3, C3, P3, O1; central: Fz, Cz, Pz, Oz; right: F4, C4, 285 P4, O2), and anterior-posterior position (frontal: F3, Fz, F4; central: C3, Cz, C4; parietal: P3, Pz, 
286 P4; occipital: O1, Oz, O2). Mean voltages per participants and time-windows were subjected to

287 mixed ANOVAS with the factors Webpage Aesthetics (aesthetic vs. unaesthetic), lateral-central

288 (lateral vs. central), and anterior-posterior (anterior vs. posterior) as repeated measures factors

289 and Group (expert vs. layperson) as between-group factor.

Results

291

292

293

294

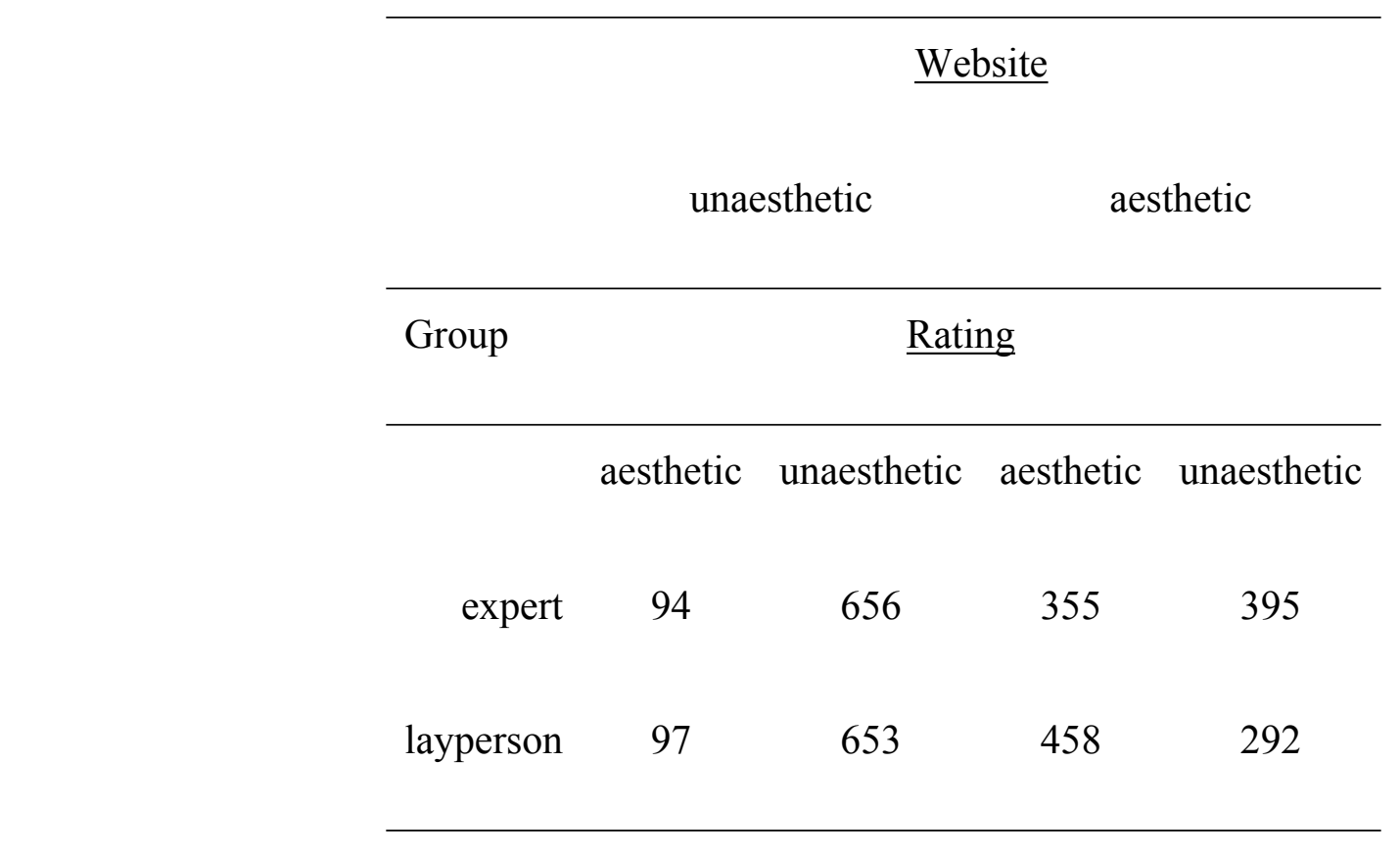

\section{Behavioral Data}

Experts and laypersons evaluated unaesthetic webpages similarly but differed in their evaluations concerning aesthetic webpages (see Table 1). A generalized linear mixed logistic regression model was calculated (Barr, Levy, Scheepers \& Tily, 2013; Jaeger, 2008).

Table 1: Frequency of aesthetic evaluations as a function of conditions 
299 effects. Random slope and random intercepts for participants and webpage were realized.

300 Dependent variable was the aesthetic evaluation by the participant. The stepwise inclusion of the

301 predictor Webpage Aesthetics and the interaction of Group and Webpage Aesthetics resulted in a

302 significant increase of fit $\left(\chi^{2}(7)=97.58, p<.001 ; \chi^{2}(8)=8.09, p=.005\right.$, respectively, see Table

3032 for a summary). The Odds ratio for the predictor Webpage Aesthetics changes by a factor of

30412.94 as the webpage aesthetics changes from aesthetic to unaesthetic. The significant interaction

305 shows that the Odds Ratio for an aesthetic evaluation changes by a factor of 1.88 depending on

306 group membership but only if an aesthetic webpage is being evaluated. In sum, experts evaluated

307 aesthetic webpages more often as unaesthetic compared to laypersons.

Table 2: Summary regression analysis

\begin{tabular}{|c|c|c|c|c|}
\hline effect & $\beta$ & $\operatorname{SE}(ß)$ & Odds Ratio & $p$-value \\
\hline Intercept & -2.30 & .24 & 0.10 & $<.001$ \\
\hline Group & -.03 & .23 & .97 & \\
\hline Webpage Aesthetics & 2.56 & .28 & 12.94 & $<.001$ \\
\hline Group x Webpage Aesthetics & .63 & .22 & 1.88 & $<.01$ \\
\hline
\end{tabular}

309

310 For the sake of completeness and in addition to the error rates and ERP-analyses, we

311 analyzed the reaction times (RTs). Keep in mind that the RTs reflect the endpoint of perceptual,

312 evaluative and decision processes. Furthermore, the RTs were much longer than the analyzed

313 EEG-interval and were not speeded. That precludes a direct comparison of both measurements.

314 RTs and ERPs probably reflect different processes. We used trimmed mean RT (trimming: 10\%) 
315 per participant, level of expertise (expert, layperson) and response (aesthetic, unaesthetic) as

316 dependent measure in a mixed ANOVA (within factor: Response; between factor: Group; see

317 Table 33 for descriptive statistics).

318 Table 3: Trimmed mean RT in ms and SD (in parentheses) as a function of level of expertise and 319 response

\begin{tabular}{lcc}
\hline & \multicolumn{2}{c}{ Response } \\
\cline { 2 - 3 } Group & aesthetic & unaesthetic \\
\hline expert & $4388(45)$ & $4069(69)$ \\
layperson & $3605(31)$ & $4202(45)$ \\
\hline
\end{tabular}

321 The results of the ANOVA showed that experts (mean: 4229 ms, SD: 173) responded

322 slower than laypersons (mean: $3904 \mathrm{~ms}, \mathrm{SD}: 309 ; F(1,18)=461.38, p<.001, \eta^{2}=.923$.

323 Aesthetic responses (mean: 3997 ms, SD: 403) were faster than unaesthetic ones (mean: 4136

324 ms, SD: $\left.89 ; F(1,18)=74.01, p<.001, \eta^{2}=.687\right)$. Both main effects were qualified by a

325 significant interaction $\left(F(1,18)=800.46, p<.001, \eta^{2}=.959\right)$. This interaction reflects the fact

326 that experts and layperson showed different response patterns. While experts were faster in

327 judging a webpage as unaesthetic than as aesthetic, laypersons showed the opposite pattern (see

328 Figure 1). Laypersons were faster in judging a webpage as aesthetic than as unaesthetic than 329 experts. 


\section{EEG-Data}

331

The continuous EEG-signal was split up in five different time windows: $80 \mathrm{~ms}-105 \mathrm{~ms}$,

$332110 \mathrm{~ms}-130 \mathrm{~ms}, 150 \mathrm{~ms}-370 \mathrm{~ms}, 370 \mathrm{~ms}-600 \mathrm{~ms}$ and $600 \mathrm{~ms}-800 \mathrm{~ms}$ after stimulus onset.

333 We used mean amplitude of each time window as dependent variable in separate mixed

334 ANOVAs with the factors Webpage Aesthetics (aesthetic vs. unaesthetic), lateral-central (lateral

335 vs. central), and anterior-posterior (anterior vs. posterior) as repeated measures factors and

336 Group (expert vs. layperson) as between-group factor. Greenhouse-Geisser corrected degrees of

337 freedom are reported in case of a sphericity assumption violation. We only report (near)

338 significant results of experimentally manipulated factors to allow for an easier overview of the

339 results (Table 4). Figure 2 and Figure 3 show the EEG-signal averaged in the regions of interest

340 (Figure 2: anterior, central, parietal, occipital; Figure 3: left, central, right).

341

Table 4. Summary of EEG findings in terms of F-values

\begin{tabular}{lccc}
\hline Time window & Group & Webpage & Group X Webpage \\
\hline $80-105 \mathrm{~ms}$ & 4.28 & 1.52 & 1.07 \\
$110-130 \mathrm{~ms}$ & $4.98^{*}$ & $4.49 *$ & 0.12 \\
& & & \\
$150-370 \mathrm{~ms}$ & $4.82 *$ & $32.43^{* * *}$ & 2.33 \\
& & & 0.00 \\
$370-600 \mathrm{~ms}$ & $6.22 *$ & $6.60 *$ & \\
& & & 0.03 \\
$600-800 \mathrm{~ms}$ & 0.12 & 0.35 & \\
& & & \\
\hline
\end{tabular}

Note: $*=$ Effect significant at .05 level; $* * *=$ Effect significant at .001 level; $\mathrm{df}=1,18$ 
345 electrodes than at parietal and occipital electrodes. At occipital electrodes, this peak is negative

346 for experts and positive for laypersons. Nonetheless, the main effect of Group fails significance

347 levels $\left(F(1,18)=4.28, p=.053, \eta_{p}^{2}=.19\right)$ as does the interaction of Group and Anterior-

348 Posterior $\left(F(1,18)=2.64, p=.058, \eta_{p}^{2}=.13\right)$. Neither the main effect Webpage nor the

349 interaction of Group and Webpage are significant $\left(F(1,18)=1.52, p=.233, \eta_{p}^{2}=.08 ; F(1,18)=\right.$

$3501.07, p=.314, \eta_{p}^{2}=.06$ ). There are no further significant interactions involving Group or

351 Webpage $(p>.224$ at least).

\section{Time window $110 \mathrm{~ms}-130 \mathrm{~ms}$ after stimulus onset}

In this time-window, we see a positive going peak at around $120 \mathrm{~ms}$. It is more

pronounced over right than over left electrodes and over parietal and occipital than central and anterior electrodes. Again, there seems to be a differentiation between experts and laypersons at occipital electrodes. Aesthetically evaluated webpages resulted in a more negative going ERP than unaesthetically evaluated webpages $\left(F(1,18)=4.49, p=.048, \eta_{p}^{2}=.20\right)$. Laypersons have a more positive ERP than experts in this time window $\left(F(1,18)=4.98, p=.039, \eta_{p}^{2}=.22\right)$. The interaction of Group and Webpage was not significant $(\mathrm{F}<1)$. There are no further significant 360 interactions.

\section{Time window $150 \mathrm{~ms}-\mathbf{3 7 0} \mathrm{ms}$ after stimulus onset}

363 effects of Group and Webpage are both significant while the interaction of Group and Webpage 
364 is not significant $\left(F(1,18)=4.82, p=.042, \eta_{p}^{2}=.21 ; F(1,18)=32.43, p=.001, \eta_{p}^{2}=.64\right.$;

$365 F(1,18)=2.33, p=.145, \eta_{p}^{2}=.11$; respectively). Experts and aesthetic websites evoke more

366 negative ERPs than laypersons and unaesthetic webpages. There are significant interactions of

367 Webpage, lateral-central and anterior-posterior Electrode Positions $\left(F(2,36)=3.31, p=.048, \eta_{p}^{2}\right.$

$\left.368=.15 ; F(1.44,25.99)=17.22, p<.001, \eta_{p}^{2}=.49\right)$. All other interactions are not significant.

369 Follow up analyses with Webpage and Electrode Position serving as factors show

370 significant effects of Webpage for each lateral-central Electrode Position (left: $F(1,18)=29.41$,

$371 p<.001, \eta_{p}^{2}=.62$; right: $F(1,18)=32.33, p<.001, \eta_{p}^{2}=.64$; central: $F(1,18)=31.04, p<.001$

$\left.372 \eta_{p}^{2}=.63\right)$. Lateral-central Electrode Position and Webpage are also significant (aesthetic: $F(2,36)$

$373=22.45, p<.001, \eta_{p}^{2}=.56$; unaesthetic: $\left.F(2,36)=11.69, p<.001, \eta_{p}^{2}=.39\right)$. Concerning the

374 other significant interactions between Webpage and anterior-posterior Electrode Position,

375 follow-up analyses reveal significant effects of Webpage on frontal, central and parietal but not

376 on occipital electrodes (frontal: $F(1,18)=39.01, p<.001, \eta_{p}^{2}=.68$; central: $F(1,18)=44.78, p$

$377<.001, \eta_{p}^{2}=.71$; parietal: $F(1,18)=26.80, p<.001, \eta_{p}^{2}=.60$; occipital: $F(1,18)=.66, p=.426$

$\left.378 \eta_{p}^{2}=.04\right)$. There was also a significant effect of Webpage at anterior-posterior Electrode Position

379 (aesthetic: $F(1.29,23.20)=33.72, p<.001, \eta_{p}^{2}=.65$; unaesthetic: $F(1.38,24.86)=25.19, p<$

$\left.380.001, \eta_{p}^{2}=.58\right)$

\section{Time window $370 \mathrm{~ms}-600 \mathrm{~ms}$ after stimulus onset}

382

In this time window, the EEG-amplitudes are less pronounced than in the previous time

windows and are getting more positive. While at frontal electrodes, the EEG-waves turn from

384 positive voltages to negatives ones, the opposite pattern is seen at occipital electrodes. The

385 differences between the aesthetic and unaesthetic evaluations are reduced compared to previous 
386 time windows. With respect to lateral and central electrodes, the EEG becomes less negative at

387 left electrodes, while there is little change in amplitude at central or right electrodes. As before,

388 aesthetic webpages exhibit a more negative EEG as unaesthetic webpages $(F(1,18)=6.60$,

$\left.389 p=.019, \eta_{p}^{2}=.27\right)$. Experts show a more negative EEG than laypersons $(F(1,18)=6.22$,

$\left.390 p=.023, \eta_{p}^{2}=.26\right)$. The interaction of Webpage and anterior-posterior Electrode Position is also

391 significant $\left(F(1.51,27.1)=9.98, p=.001, \eta_{p}^{2}=.36\right)$. The remaining interactions are not

392 significant.

393 Follow up analyses show that aesthetic webpages differ from unaesthetic webpages at

394 frontal $\left(F(1,18)=6.82, p=.018, \eta_{p}^{2}=.28\right)$, central $\left(F(1,18)=19.60, p<.001, \eta_{p}^{2}=.52\right)$ and

395 parietal position $\left(F(1,18)=4.85, p=.041, \eta_{p}^{2}=.21\right)$, but not at occipital electrode positions

$396(F<1)$. Moreover, there is a significant effect for anterior-posterior Electrode Position for

397 aesthetic as well as unaesthetic Webpages $\left(F(1.41,25.39)=6.74, p=.009, \eta_{p}^{2}=.27 ; F(1.64\right.$,

$\left.39829.57)=5.56, p=.013, \eta_{p}^{2}=.24\right)$.

\section{Time window $600 \mathrm{~ms}-800 \mathrm{~ms}$ after stimulus onset}

400

In this time window, the EEG comes from a negative voltage range into a positive one at

frontal and central electrodes while the EEG at occipital electrodes shows the opposite patterns.

402 The EEG at parietal electrodes fluctuates around zero. There are no main effects, but a

403 significant interaction of Webpage and anterior-posterior Electrode Position $(F(1.87,33.58)=$

$4044.00, p=.030, \eta_{p}^{2}=.18$ ). Follow up analysis on this interaction reveals a significant effect of

405 anterior-posterior Electrode position for aesthetic as well as unaesthetic Webpages $(F(1.47$,

$\left.40626.44)=4.61, p=.028, \eta_{p}^{2}=.20 ; F(1.67,30.02)=7.69, p=.003, \eta_{p}^{2}=.30\right)$. 


\section{Discussion}

We asked design-experts and laypersons to evaluate the aesthetic properties of static

webpages that varied in aesthetic attractiveness. Behavioral responses, i.e. judgements about a

410 webpage's attractiveness, and electrophysiological responses were recorded. The ERPs show

411 early differences between experts and laypersons. We will first summarize behavioral and

412 electrophysiological results before discussing these findings in the context of the models of

413 aesthetic processing presented above.

Participants' behavioral responses indicated that they were more critical than anticipated.

415 Although we presented an even number of aesthetic and unaesthetic webpages, unaesthetic

416 judgements prevailed. Laypersons and experts evaluate unaesthetic webpages similarly. In case

417 of aesthetic webpages, experts seemed to be more critical than laypersons given that they

418 evaluated more webpages as unaesthetic than laypersons did. Nonetheless, the major factor

419 driving the evaluation is the aesthetic quality of the webpage itself, not the person evaluating the

420 webpage as indicated by the 6-7 times larger odds ratio for webpage aesthetic than the odds-ratio

421 for group membership. Given this, expertise is less important than aesthetics in evaluating a

422 webpage.

As the design of this study is not aimed at analyzing RTs, we shortly discuss RTs to

ensure completeness but do not want to overemphasize the results. The differences in RTs might

be interpreted in a way that experts need more time to make a decision on aesthetics because

they scrutinize the aesthetics-relevant details of a webpage more carefully than laypersons do

427 which goes along with underlying attention processes (Chatterjee, 2004). Experts are more

428 demanding and have a high standard in regards of the aesthetic quality of a webpage. They have

429 learned to evaluate if a stimulus achieves their standard faster than laypersons. Yet because of 
430 their more thorough processing, their decisions are slower. In contrast, laypersons are faster with

431 their decision because they process the webpage in a more superficial way than experts do but

432 they lack a clear standard or expectations, which leads to longer RTs for unaesthetic webpages.

433 Notice that there was an interaction in the RT-analysis of group and aesthetics while we

434 observed only main effects of group and aesthetics in the ERPs. Thus, it is not likely that the

435 group differences observed in the ERPs are directly linked the RTs. Rather either additional

436 processes not yet reflected in the ERPs contribute to the RTs or the processes reflected by the

437 ERPs undergo further modification. Thus, the processes picked up by ERPs are only the starting

438 point of processing not the end.

Electrophysiological responses showed no significant differences between experts and

laypersons in the earliest time-window. However, even at around $100 \mathrm{~ms}$ aesthetically evaluated

webpages result in stronger ERPs than unaesthetically evaluated ones. In terms of scalp

442

distribution, this effect is not modulated by electrode position. In contrast, effects starting at

443 around $150 \mathrm{~ms}$ and lasting to $600 \mathrm{~ms}$ show interactions between electrode position and aesthetic

evaluation. An aesthetic evaluation results in a more negative evaluation at frontal, central and

parietal electrodes than at occipital electrodes. This pattern reverses independently of aesthetic

447 temporal and large spatial distribution of the effects indicate that various, interconnected cortical 448 areas are involved in aesthetic processing (Kawabata \& Zeki, 2004).

The data are inconclusive with respect to emotion-related potential such as the ERAN

450 and the LPP. The ERAN starts $300 \mathrm{~ms}$ to $400 \mathrm{~ms}$ after stimulus onset being more negative for

451 unattractive stimuli than for attractive ones (Höfel \& Jackobsen, 2007a). We see the opposite

452 pattern here. Unaesthetic webpages elicit more positive ERPs starting at a little over $100 \mathrm{~ms}$ 
453 lasting up to $600 \mathrm{~ms}$. The difference between unaesthetic and aesthetic webpages is more

454 pronounced over frontal to parietal areas than over occipital areas while there is no lateralization 455 of the effect. The direction of the effect and its distribution differ from that of an ERAN. The 456 LPP is often prominent over parietal to central electrodes (Foti, Hajcak \& Dien, 2009). It is

457 larger for emotional stimuli than for neutral stimuli. We see a decrease in positivity starting at 458 around $300 \mathrm{~ms}$ at parietal electrodes. This is accompanied by a decrease in negativity over 459 central electrodes in the same time range. However, a neutral baseline is missing which would 460 allow determining whether these changes are driven by emotional content. In addition, the 461 observed pattern differs from that reported for a LPP (e.g. Weinberg \& Hajcak, 2010). Thus, it is 462 rather unlikely that we observed a LPP.

\section{Experts versus laypersons}

Modern theories of aesthetic processing assume an interaction of perceiver and object such that experts should process objects differently than laypersons. Our data partly support this assumption. Experts were more critical than laypersons as indicated by the behavioral data. However, a similar interaction of expertise and aesthetic evaluation, for instance greater group differences for aesthetic webpages than for unaesthetic webpages, is absent in the ERPs. This

469 pattern would have been predicted by recent theories of aesthetic processing (Chatterjee, 2004; Leder et al., 2004; Reber et al., 2004). The main effects of Group and Webpage suggest that the

471 neuronal generators underlying the ERPs are basically the same but experts process the stimuli in 472 a more thorough manner.

474 studies (e.g., Hekkert et al., 1994; Hekkert \& van Wieringen, 1996a; Hekkert \& van Wieringen, 475 1996b; Phiko et al., 2011; Winston \& Cupchik, 1992). For instance, it has been suggested that 
476 experts have enhanced associative knowledge that is easily accessible (Cheung \& Bar, 2012;

477 Harel et al., 2010; Long et al., 2011, Tanaka \& Taylor, 1991). Such enhanced memory

478 representations might be activated when processing the presented webpages. Furthermore,

479 motivational and attentional differences might contribute to the observed difference. Harel et al.

480 (2010) showed that expertise influences neuronal activation mainly when the expertise is task-

481 relevant. Therefore, it is not a bottom-up, stimulus-driven processing mechanism that differs

482 between experts and laypersons but rather a top-down (i.e. task demands) modulated processing

483 that results in intensified processing. If this explanation holds, experts and laypersons should not

484 differ when the expertise is not task-relevant as it was in the current study.

\section{Aesthetics of webpages}

Various attempts to obtain an objective measure of the aesthetic value of an object can be

487 found in Altaboli and Lin (2011), Ngo, Samsudin, and Abdullah (2000) or Seckler, Opwis, and

488 Tuch, (2015). We used an aesthetics g-factor approach (measured with the VisAWI-S, Moshagen

$489 \&$ Thielsch, 2013) to divide the webpages in aesthetic and unaesthetic ones. Thus, we are not

490 able to determine which of the suggested dimensions (or which combination of dimensions)

491 brought about the observed behavioral and electrophysiological differences between aesthetic

492 and unaesthetic webpages.

493 Aesthetic and unaesthetic webpages elicit different EEG-amplitude in an early time-

494 window of $110 \mathrm{~ms}$ to $130 \mathrm{~ms}$. ERPs in this time window presumably reflect processing of

495 stimulus properties such as contrast or brightness (e.g. Luck, 2005). Often such early visual

496 processes are expressed most over occipital electrodes, which is not what we observe here. We

497 observe a frontal to parietal distribution sparing occipital electrodes. This distributional pattern

498 suggests that not visual properties such as contrast or brightness brought about these differences. 
499 However, aesthetic and unaesthetic webpages differed in complexity measured in bytes with

500 unaesthetic webpages being more complex than aesthetic ones. High visual complexity usually

501 results in a more negative evaluation than medium to less complexity (Tuch et al., 2012a).

502 Therefore, this early differentiation might reflect visual complexity. But keep in mind, that our

503 complexity measure might be rather crude and probably does not reflect functional complexity.

504 Other properties could bring about the observed difference.

For instance, it might be that (aesthetic) webpages exhibit fractal-like image properties,

as do graphic art or natural scenes (Redies, Hasenstein \& Denzler, 2007). Redies et al. (2007)

507 link such fractal-like image properties to the aesthetic perception. A theory of aesthetic

508 processing must take into account human sensory processing. Consequently, web-designer and

509 artists exploit such image-properties because the human visual system has evolved that way. It

510 remains to be determined whether webpages exhibit fractal-like properties and whether they

511 differentiate aesthetic and unaesthetic webpages. Keep in mind that fractal-like image properties

512 are probably one of many properties contributing to an aesthetic evaluation. Whether they are

513 necessary or sufficient for an aesthetic evaluation needs to be determined (Redies et al., 2007).

514 The early differentiation we observed here is in contrast to theories put forward by

515 Chatterjee (2004) or Leder et al. (2004) who do not assume an influence of aesthetic properties

516 on early processing. More in line with these assumptions are the results by Höfel and Jacobsen

517 (2007). They observed a differentiation of ERPs to aesthetic and unaesthetic picture starting at

518 around 300 ms after stimulus onset (see also Jacobsen \& Höfel, 2003 using the same stimuli but

519 a different task for a similar time pattern). The stimuli, Höfel and Jacobsen (2007) employed,

520 were black-white symmetric and asymmetric patterns instead of colored webpages as we used. 
521 Such stimuli apparently elicit similar ERP-patterns but they might miss properties that the

522 webpages employed here had, for instance, different degree of complexity, color and so on.

Some studies in this area (Lindgaard et al., 2006, 2011; Tractinsky, 2006; etc.) have

524 presented stimuli for very brief period of $50 \mathrm{~ms}$ duration (Tuch et al., 2012a even for $17 \mathrm{~ms}$ ).

525 Evaluations of these shortly presented stimuli were quite stable - but it is not to be supposed that

526 the cognitive processing of these stimuli only takes $50 \mathrm{~ms}$. Based on our data, we assume that

527 evaluation is a process that lasts for several hundred milliseconds, but can be initiated even with

528 brief presentation durations.

We argued above that experts have enhanced, widely distributed representations that are

easy to access. Thus, attention processes operating in a form of a feed-forward sweep might have influenced aesthetic evaluation processes already early on (Chatterjee, 2004). However, this would imply an interaction of expertise and webpage aesthetics that was absent here. The aesthetic evaluation is probably based on a variety of stimulus properties that are processed in a

534 bottom-up manner first (Douneva, Jaron \& Thielsch, 2016; Thielsch \& Hirschfeld, 2012) before top-down processes kick in. It is rather unlikely, that bottom-up processing affects stimulus

536 processing over the whole analysis period. Rather, evaluative impression formation and evaluative categorization take place in this period (Cela-Conde et al., 2004; Jacobsen \& Höfel, 2003). However, the long lasting difference between aesthetic and unaesthetic webpages prohibits relating cognitive processes to time periods in a fine-grained manner. The spatial

540 distribution of the ERP-effect observed is of little help. Spatial and temporal distributions of

541 ERP-effects allow only relatively gross classification. Evaluative processes might bring about the 542 interaction of aesthetic and anterior-posterior activation in the time-window of $150 \mathrm{~ms}-600 \mathrm{~ms}$. 
543 The occipital activation in the earlier time-window might reflect mainly processing of aesthetic

544 stimulus properties.

545 Aesthetic webpages elicited more negative ERP than unaesthetic ones. There is a more

546 negative going ERP at central to lateral electrodes in a time-window of $150 \mathrm{~ms}$ to $370 \mathrm{~ms}$ after

547 stimulus onset for aesthetic compared to unaesthetic webpages. Cela-Conde et al. (2004) but also

548 Jacobsen and Höfel (2003) observed much more temporally and spatially distinct differences

549 between aesthetic and unaesthetic stimuli than we did. Jacobsen and Höfel observed a more

550 negative going ERP when participants viewed unaesthetic stimuli. However, they compared

551 "beautiful" decisions to "symmetric"-decision. The different temporal and spatial distribution

552 might be due to the employed task. In addition, while we used linked mastoids as reference

553 electrode, Jacobsen and Höfel used the nose tip as reference electrode. That prevents re-

554 referencing our data to their setup. Thus, the differences in spatial distribution might simply be

555 due to reference differences.

$556 \quad$ Cela-Conde et al. (2004) observed effects starting at around $400 \mathrm{~ms}$ to $900 \mathrm{~ms}$ after

557 stimulus onset while participants observed aesthetic (rated beautiful) stimuli. The late onset

558 might be due to using artistic and non-artistic stimuli instead of "everyday" aesthetic and

559 unaesthetic stimuli. Furthermore, the spatial differences probably result from the fact that Cela-

560 Conde et al. used MEG, a reference-free measure and equivalent dipoles in the source space to

561 determine the spatial distribution. The "relatively" small number of electrodes that we used

562 prohibits source-location. In sum, task, stimuli and recording technique might contribute to the

563 observed differences. 


\section{Conclusions}

565 The relevant aesthetic theories (Chatterjee, 2004; Leder et al., 2004; Reber et al., 2004)

566 predict an interaction between recipient characteristics and stimulus properties. Leder et al.

567 assume that an aesthetic form should facilitate perceptual and cognitive processing given

568 expertise (see also Reber et al., 2004). More expertise should result in less cognitive effort, hence

569 in less neuronal activation. We could not find such interaction; rather we observed only main

570 effects of recipient characteristics and of stimulus properties. Also not anticipated, experts

571 showed more activation than laypersons. One might assume, that the observed activation reflects

572 the broader and better-connected associative network that experts supposedly develop (Cheung

573 \& Bar, 2012; Harel, et al., 2010). Nonetheless, differences between aesthetically and

574 unaesthetically judged webpages emerge much earlier than anticipated.

575 
577 Altaboli, A. \& Lin, Y. (2011). Objective and Subjective Measures of Visual Aesthetics of 578 Website Interface Design: The Two Sides of the Coin. In J.A. Jacko (Ed.): HumanComputer Interaction (pp. 35-44), Heidelberg: Springer.

Arnheim, R. (1974). Art and visual Perception: A psychology of the creative eye. Berkeley: University of California Press.

Barr, D. J., Levy, R., Scheepers, C. \& Tily, H. J. (2013). Random effect structures for confirmatory hypothesis testing: Keep it maximal. Journal of Memory and Language, 68,

Bentin, Sh, Allison, T., Puce, A. Perez, E. \& McCarthy, G. (1996). Electrophysiological Studies of Face Perception in Humans. Journal of Cognitive Neuroscience, 8, 551-565.

Berlyne, D. E. (1971). Aesthetics and Psychobiology. New York: Appleton-Century-Crofts.

Birkhoff, G. D. (1933). Aesthetic measure. Cambridge: Harvard University Press

Bloch, P. H., Brunel, F. F. \& Arnold, T. J. (2003). Individual differences in the centrality of visual product aesthetics: Concept and measurement. Journal of Consumer Research, 29, 551- 565 .

Carretié, L., Mercado, F., Tapia, M. \& Hinojosa, J. A. (2001). Emotion, attention and the 'negativity bias', studied through event-related potentials. International Journal of Psychophysiology, 41(1), 75-85. doi:10.1016/S0167-8760(00)00195-1 
596 Carretié, L., Hinojosa, J. A., Martín-Loeches, M., Mercado, F., \& Tapia, M. (2004). Automatic 597 attention to emotional stimuli: Neural correlates: Automatic Attention to Emotional 598 Stimuli. Human Brain Mapping, 22(4), 290-299. doi:10.1002/hbm.20037

599 Cela-Conde, C. J., Marty, G., Maestú, F., Ortiz, T., Munar, E., Fernández, A., ... Quesney, F. 600 (2004). Activation of the prefrontal cortex in the human visual aesthetic perception. $601 \quad$ Proceedings of the National Academy of Sciences of the United States of America, 101(16), 602 6321-6325. http://doi.org/10.1073/pnas.0401427101

603 604 605 606 607 608 609

Chatterjee, A. (2004). Prospects for a Cognitive Neuroscience of Visual Aesthetics. Bulletin of Psychology and the Arts, 4(2), 55-60. doi: 10.1037/e514602010-003

Cheung, O. S. \& Bar, M. (2012). Visual prediction and perceptual expertise. International Journal of Psychophysiology, 83, 156-163. doi: 10.1016/j.ijpsycho.2011.11.002

Chevalier, A. \& Ivory, M. Y. (2003). Web site designs: Influences of designer's expertise and design constraints. International Journal of Human - Computer Studies, 58, 57-87. doi: 10.1016/S1071-5819(02)00126-X

de Tommaso, M., Pecoraro, C., Sardaro, M., Serpino, C., Lancioni, G. \& Livrea, P. (2008). Influence of aesthetic perception on visual event-related potentials. Consciousness and Cognition, 17, 933-945. doi:10.1016/j.concog.2007.09.003

Douneva, M., Jaron, R. \& Thielsch, M.T. (2016). Effects of different website designs on first impressions, aesthetic judgments, and memory performance after short presentation. Interacting with Computers, 28 (4), 552-567. doi: 10.1093/iwc/iwv033

Eysenck, H. (1941). The empirical determination of an aesthetic formula. Psychological Review, $48,83-92$. 
618 Fechner G. T. (1876). Vorschule der Aesthetik [Experimental Aesthetics; "Pre-school" of

619 aesthetics]. Leipzig: Breitkopf \& Härtel

620 Foti, D., Hajcak, G., \& Dien, J. (2009). Differentiating neural responses to emotional pictures:

621 Evidence from temporal-spatial PCA. Psychophysiology, 46(3), 521-530. doi:

622 10.1111/j.1469-8986.2009.00796.x

623 Gauthier, I., Skudlarski, P., Gore, J., Anderson, A. W. (2000). Expertise for cars and birds 624

625 recruits brain areas involved in face recognition. Nature Neuroscience, 3, 191-197. doi: $10.1038 / 72140$

Gombrich, E. H. (1995). The Story of art. London: Phaidon.

Handy, T. C., Smilek, D., Geiger, L., Liu, C. \& Schooler, J. W. (2010). ERP evidence for rapid 630 hedonic evaluation of logos. Journal of Cognitive Neuroscience, 22(1), 124-138.

Harel, A., Gilaie-Dotan, S., Malach, R. \& Bentin, S. (2010). Top-down engagement modulates the neural expressions of visual expertise. Cerebral Cortex, 20(10), 2304-2318. doi:

633 10.1093/cercor/bhp316

Hasse, C. \& Weber, R. (2012). Eye movements on facades: The subjective perception of balance in architecture and its link to aesthetic judgment. Empirical Studies of The Arts, 30(1), 722. doi:10.2190/EM.30.1.c of the appraisal of cubist paintings. British Journal of Psychology, 81, 483-495. doi: 
640 Hekkert, P., Snelders, D. \& Wieringen, P. C. W. (2003). 'Most advanced, yet acceptable':

641 Typicality and novelty as joint predictors of aesthetic preference in industrial design.

642 British Journal of Psychology, 94, 111-124. doi: 10.1348/000712603762842147

643 Hekkert, P., \& van Wieringen, P. C. (1996a). The impact of level of expertise on the evaluation 644 of original and altered versions of post-impressionistic paintings. Acta Psychologica, 94, 117-131. doi:10.1016/0001-6918(95)00055-0

646

647

648

649

650

651

652

653

654

655

656

657

658

659

660

Hekkert, P., \& Van Wieringen, P. C. (1996b). Beauty in the eye of expert and nonexpert beholders: A study in the appraisal of art. The American Journal of Psychology, 109, 389407. doi: $10.2307 / 1423013$

Höfel, L. \& Jacobsen, T. (2007a). Electrophysiological indices of processing aesthetics: Spontaneous or intentional processes? International Journal of Psychophysiology, 65(1), 20-31. doi: 10.1016/j.ijpsycho.2007.02.007

Höfel, L. \& Jacobsen, T. (2007b). Electrophysiological indices of processing symmetry and aesthetics. Journal of Psychophysiology, 21(1), 9-21. doi: 10.1027/0269-8803.21.1.9

Hoyer, W. D. \& Stokburger-Sauer, N. E. (2012). The role of aesthetic taste in consumer behavior. Journal of The Academy of Marketing Science, 40(1), 167-180. doi:10.1007/s11747-011-0269-y

Huang, Y. X., \& Luo, Y. J. (2006). Temporal course of emotional negativity bias: an ERP study. Neuroscience letters, 398, 91-96. doi:10.1016/j.neulet.2005.12.074

ISO (2006). ISO 9241: Ergonomics of Human-System Interaction - Part 151: Guidance on World Wide Web Interfaces. Geneva: International Organisation for Standardisation. 
661 Jacobsen, T. \& Höfel, L. (2003). Descriptive and evaluative judgment processes: Behavioral and

662 electrophysiological indices of processing symmetry and aesthetics. Cognitive, Affective \& 663 Behavioral Neuroscience, 3(4), 289-299. doi: 10.3758/CABN.3.4.289

664 Jacobsen, T. (2006). Bridging the Arts and Sciences: A Framework for the Psychology of 665 Aesthetics. Leonardo, 39, 155-162.

666 Jacobsen, T. (2010). Beauty and the brain: culture, history and individual differences in aesthetic 667 appreciation. Journal of Anatomy, 216(2), 184-191

668 Jaeger, T. F. (2008). Categorical data analysis: Away from ANOVAs (transformations or not) 669 and towards logit mixed models. Journal of Memory and Language, 59, 434 - 446. doi:

670 10.1016/j.jml.2007.11.007

671 Kawabata, H. \& Zeki, S. (2004). Neural correlates of beauty. Journal of Neurophysiology, 91, 672 1699-1705. doi: 10.1152/jn.00696.2003

673 Kirk, U., Skov, M., Christensen, M. S., \& Nygaard, N. (2009). Brain correlates of aesthetic expertise: a parametric fMRI study. Brain and Cognition, 69, 306-315.

675 doi:10.1016/j.bandc.2008.08.004

Kowatari, Y., Lee, S. H., Yamamura, H., Nagamori, Y., Levy, P., Yamane, S., \& Yamamoto, M.

677 (2009). Neural networks involved in artistic creativity. Human Brain Mapping, 30, 1678-

678 1690. doi: 10.1002/hbm.20633

679

Kozbelt, A., Dexter, S., Dolese, M. \& Seidel, A. (2012). The aesthetics of software code: A 680 quantitative exploration. Psychology of Aesthetics, Creativity, and The Arts, 6(1), 57-65.

681 doi:10.1037/a0025426 doi: 10.1037/a0025426 
682 Lavie, T. \& Tractinsky, N. (2004). Assessing Dimensions of Perceived Visual Aesthetics of Web 683 Sites. International Journal of Human - Computer Studies, 60, 269-298. doi:

$684 \quad 10.1016 /$ j.ijhcs.2003.09.002

685 Leder, H. \& Nadal, M. (2014). Ten years of a model of aesthetic appreciation and aesthetic 686 judgments : The aesthetic episode - Developments and challenges in empirical aesthetics. 687 British Journal of Psychology, 105(4), 443-464. doi:10.1111/bjop.12084

688 Leder, H., Belke, B., Oeberst, A. \& Augustin, D. (2004). A model of aesthetic appreciation and 689 aesthetic judgements. British Journal of Psychology, 95, 489-508. doi:

690 $10.1348 / 0007126042369811$

691 Lee, S. \& Koubek, R. J. (2012). Users' perceptions of usability and aesthetics as criteria of pre692 693 and post-use preferences. European Journal of Industrial Engineering, 6(1), 87. doi: 10.1504/EJIE.2012.044812

694 695 696 697 698 699 700

Long, Z., Peng, D., Chen, K., Jin, Z., \& Yao, L. (2011). Neural substrates in color processing: A comparison between painting majors and non-majors. Neuroscience Letters, 487, 191-195. doi:10.1016/j.neulet.2010.10.020

Lindgaard, G., Dudek, C., Sen, D., Sumegi, L. \& Noonan, P. (2011). An exploration of relations between visual appeal, trustworthiness and perceived usability of homepages. $A C M$ Transactions on Computer-Human Interaction, 18(1), 1-30. doi: $10.1145 / 1959022.1959023$

Lindgaard, G., Fernandes, G., Dudek, C. \& Brown, J. (2006). Attention web designers: You have 50 milliseconds to make a good first impression! Behaviour \& Information Technology, 25(2), 115-126. doi: 10.1080/01449290500330448 
704 Luck, S. J. (2005). An Introduction to the Event-related Potential Technique. Cambridge, MA. $705 \quad$ MIT Press.

706 Marr, D. (1982). Vision: A computational investigation into the human representation and 707 processing of visual information. New York: WH Freeman and Company.

708 Miniukovich, A., \& De Angeli, A. (2015). Computation of Interface Aesthetics. Proceedings of 709 the 33rd Annual ACM Conference on Human Factors in Computing Systems - CHI'15, 710 1163-1172. doi:10.1145/2702123.2702575

711 Moshagen, M. \& Thielsch, M. T. (2010). Facets of visual aesthetics. International Journal of Human-Computer Studies, 68 (10), 689-709. doi: 10.1016/j.ijhcs.2010.05.006

713 Moshagen, M. \& Thielsch, M. T. (2013). A short version of the visual aesthetics of websites inventory. Behaviour \& Information Technology, 32 (12), 1305-1311. doi: 10.1080/0144929X.2012.694910

716
Müller, M., Höfel, L., Brattico, E. \& Jacobsen, T. (2009), Electrophysiological Correlates of Aesthetic Music Processing. Annals of the New York Academy of Sciences, 1169, 355-358. doi: $10.1111 / \mathrm{j} .1749-6632.2009 .04846 . x$

Müller, M., Höfel, L., Brattico, E. \& Jacobsen, T. (2010). Aesthetic judgments of music in experts and laypersons-An ERP study. International Journal of Psychophysiology, 76(1), 40-51. doi:10.1016/j.ijpsycho.2010.02.002

Ngo, D. C. L., Samsudin, A. \& Abdullah, R. (2000). Aesthetic measures for assessing graphic screens. Journal of Information Science and Engineering, 16(1), 97-116. 
724 Pang, C. Y., Nadal, M., Müller-Paul, J. S., Rosenberg, R., \& Klein, C. (2013).

725 Electrophysiological correlates of looking at paintings and its association with art

726 expertise. Biological Psychology, 93, 246-254. doi:10.1016/j.biopsycho.2012.10.013

727 Park, S., Choi, D. \& Kim, J. (2004). Critical factors for the aesthetic fidelity of web pages:

728 empirical studies with professional web designers and users. Interacting with Computers,

$729 \quad$ 16, 351-376. doi:10.1016/j.intcom.2003.07.001

730 Pihko, E., Virtanen, A., Saarinen, V. M., Pannasch, S., Hirvenkari, L., Tossavainen, T., ... \&

731 Hari, R. (2011). Experiencing art: the influence of expertise and painting abstraction level.

732 Frontiers in Human Neuroscience, 5, 1-10. doi: 10.3389/fnhum.2011.00094

733 Reber, R., Schwarz, N. \& Winkielman, P. (2004). Processing Fluency and Aesthetic Pleasure: Is

734 Beauty in the Perceiver's Processing Experience? Personality and Social Psychology

735 Review, 8(4), 364-382. doi:10.1207/s15327957pspr0804_3

736 Redies, C., Hasenstein, J. \& Denzler, J. (2007). Fractal-like image statistics in visual art:

737 similarity to natural scenes. Spatial Vision, 21(1), 137-148. doi:

738 $10.1163 / 156856808782713825$

739

740

741

742

743

744

745

Scott, L. S., Tanaka, J. W., Sheinberg, D. L., \& Curran, T. (2006). A reevaluation of the electrophysiological correlates of expert object processing. Journal of Cognitive Neuroscience, 18, 1453-1465. doi: 10.1162/jocn.2006.18.9.1453

Seckler, M., Opwis, K. \& Tuch, A. N. (2015). Linking objective design factors with subjective aesthetics: An experimental study on how structure and color of websites affect the facets of users' visual aesthetic perception. Computers in Human Behavior, 49, 375-389. doi:10.1016/j.chb.2015.02.056 
746 Silvia, P. J. \& Berg, C. (2011). Finding movies interesting: How appraisals and expertise

747 influence the aesthetic experience of film. Empirical Studies of the Arts, 29, 73-88.

$748 \quad$ doi:10.2190/EM.29.1.e

749 Silvia, P. J. (2013). Interested experts, confused novices: Art expertise and the knowledge

750 emotions. Empirical Studies of the Arts, 31, 107-115. doi: 10.2190/EM.31.1.f

751 Solso, R. L. (2003). The psychology of art and the evaluation of the conscious brain. Cambridge:

$752 \quad$ MIT Press.

753 Tanaka, J. W., Curran, T. (2001). A Neural Basis for Expert Object Recognition. Psychological

$754 \quad$ Science, 12, 43-47. doi: 10.1111/1467-9280.00308

755 Tanaka, J. W., \& Taylor, M. (1991). Object categories and expertise: Is the basic level in the eye of the beholder?. Cognitive Psychology, 23, 457-482. doi:10.1016/0010-0285(91)90016-H

757

758

759

760

761

762

763

764

765

Thielsch, M. (2008). Ästhetik von Websites: Wahrnehmung von Ästhetik und deren Beziehung zu Inhalt, Usability und Persönlichkeitsmerkmalen (Aesthetics of websites: Perception of aesthetics and its relation to content, usability and traits). Münster: MV Wissenschaft.

Thielsch, M. T. \& Hirschfeld, G. (2012). Spatial frequencies in aesthetic website evaluations explaining how ultra-rapid evaluations are formed. Ergonomics, 55 (7), 731-742. doi: $10.1080 / 00140139.2012 .665496$

Thielsch, M. T., Blotenberg, I. \& Jaron, R. (2014). User evaluation of websites: From first impression to recommendation. Interacting with Computers, 26, 89-102. doi: 10.1093/iwc/iwt033 
766 Tractinsky, N., Cokhavi, A., Kirschenbaum, M. \& Sharfi, T. (2006). Evaluating the consistency

767 of immediate aesthetic perceptions of web pages. International Journal of Human -

768 Computer Studies, 64(11), 1071-1083. doi: 10.1016/j.ijhcs.2006.06.009

769 Tuch, A. N., Bargas-Avila, J. A. \& Opwis, K. (2010). Symmetry and aesthetics in website

770 design: It's a man's business. Computers in Human Behavior, 26(6), 1831-1837.

771 doi:10.1016/j.chb.2010.07.016

772 Tuch, A. N., Bargas-Avila, J. A., Opwis, K., \& Wilhelm, F. H. (2009). Visual complexity of

773

774

775

776

777

778

779

780

781

782

783

784

785

786

787 websites: Effects on users' experience, physiology, performance, and memory. International Journal of Human-Computer Studies, 67(9), 703-715.

Tuch, A. N., Presslaber, E. E., Stöcklin, M., Opwis, K. \& Bargas-Avila, J. A. (2012a). The role of visual complexity and prototypicality regarding first impression of websites: Working towards understanding aesthetic judgments. International Journal of Human-Computer Studies, 70, 794-811. doi: 10.1016/j.ijhcs.2012.06.003

Tuch, A. N., Roth, S. P., Hornbæk, K., Opwis, K. \& Bargas-Avila, J. A. (2012b). Is beautiful really usable? Toward understanding the relation between usability, aesthetics, and affect in HCI. Computers in Human Behavior, 28(5), 1596-1607. doi: 10.1016/j.chb.2012.03.024

von Ehrenfels, C. (1890). Über Gestaltqualitäten. Vierteljahresschrift für wissenschaftliche Philosophie, 14, 249-292.

Wang, X., Huang, Y., Ma, Q. \& Li, N. (2012). Event-related potential P2 correlates of implicit aesthetic experience. NeuroReport, 23, 862-866. doi:10.1097/WNR.0b013e3283587161

Weinberg, A., \& Hajcak, G. (2010). Beyond good and evil: the time-course of neural activity elicited by specific picture content. Emotion, 10(6), 767. doi:10.1037/a0020242 
788 Winston, A. S., \& Cupchik, G. C. (1992). The evaluation of high art and popular art by naive and

789 experienced viewers. Visual Arts Research, 18, 1-14. http://www.jstor.org/stable/20715763

790 Xing, J. \& Manning, C. A. (2005). Complexity and automation displays of air traffic control:

791 Literature review and analysis. DTIC Document. Retrieved from

792 http://oai.dtic.mil/oai/oai?verb=getRecord\&metadataPrefix=html\&identifier=ADA460107

793 Zeki, S. (2001). Artistic creativity and the brain. Science, 293(5527), 51-52. doi:

794

$10.1126 /$ science. 1062331

795 
797 Figure 1: Trimmed means RT in $\mathrm{ms}$ as a function of level of expertise and response.

798 Figure 2: EEG-signal as a function of expertise, aesthetics and anterior - posterior regions of 799 interests.

800 Figure 3: EEG-signal as a function of expertise, aesthetics and left-right regions of interests.

801 
802

803

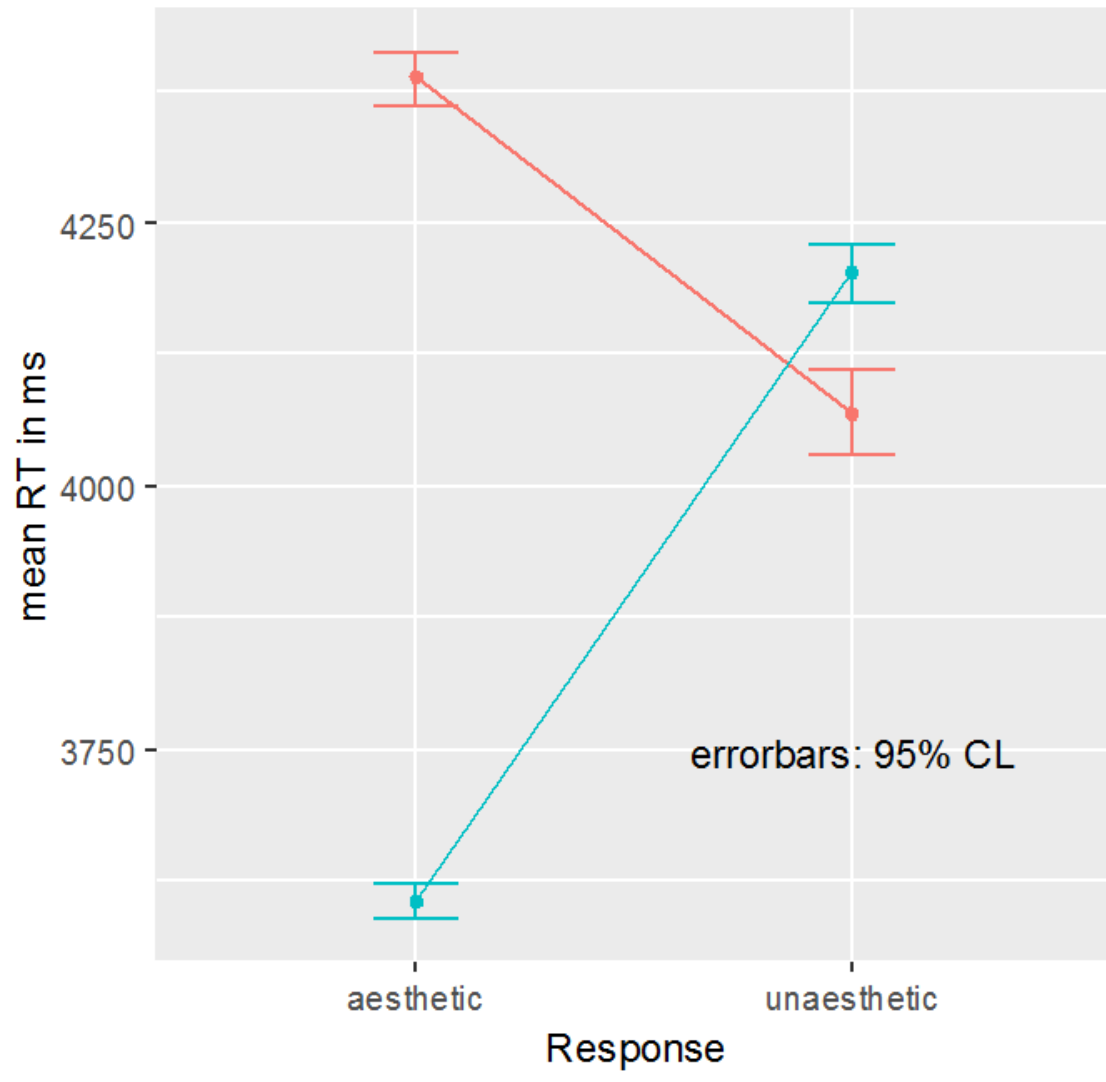

804

805
Figure 1

level of expertise

$\rightarrow$ expert

- laypers on 


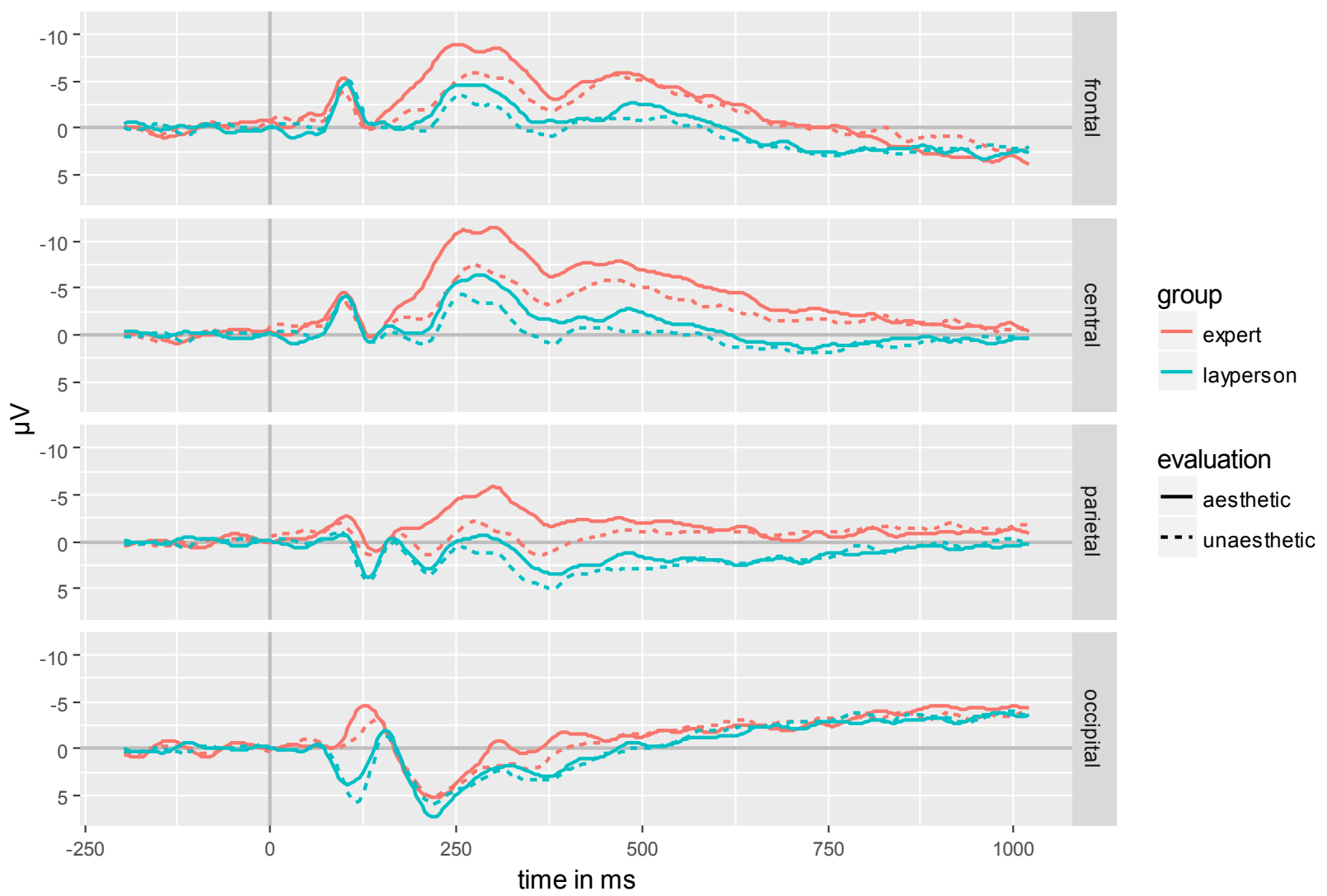

807 
Figure 3

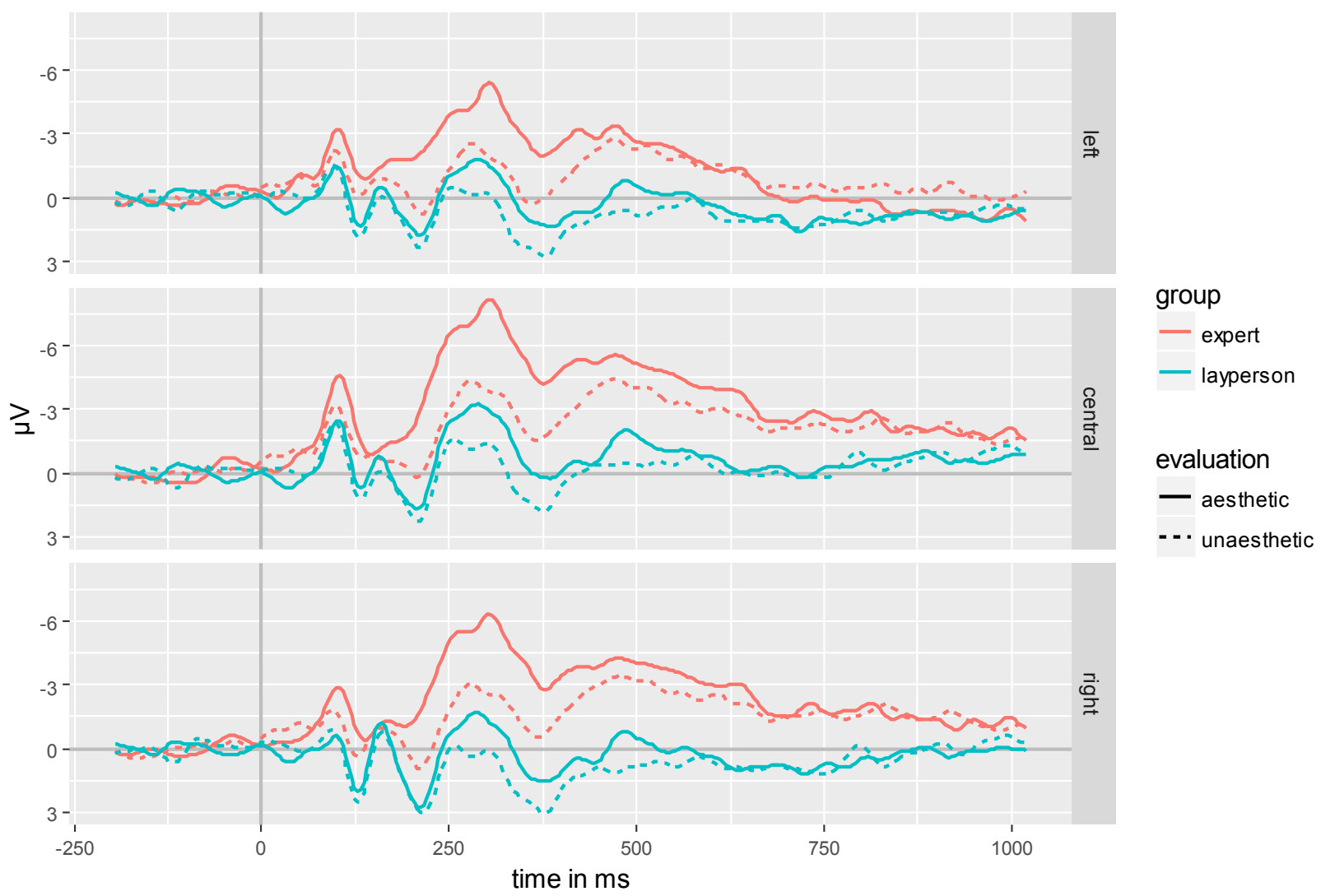


${ }^{1}$ We are aware that visual complexity measured in bytes is a crude measure of complexity. It is a numerical measure ignoring functional and practical aspects as well as the integration by the observer (see Xing and Manning, 2005, for a review of definitions of complexity). 